\title{
Influence of thixotropy determined by different test methods on formwork pressure of self-consolidating concrete
}

\author{
Murat Tuyan ${ }^{\mathrm{a}, *}$, Reza Saleh Ahari ${ }^{\mathrm{b}}$, Tahir Kemal Erdem ${ }^{\mathrm{c}}$, Özge Andiç Çakır ${ }^{\mathrm{a}}$, Kambiz Ramyar ${ }^{\mathrm{a}}$ \\ a Department of Civil Engineering, Ege University, Bornova-Izmir, Turkey \\ ${ }^{\mathrm{b}}$ Department of Civil Engineering, Tabriz Branch, Islamic Azad University, Tabriz, Iran \\ ${ }^{\mathrm{c}}$ Department of Civil Engineering, Izmir Institute of Technology, Urla-İzmir, Turkey
}

\section{H I G H L I G H T S}

- Self-consolidating concrete with varying compositions was prepared.

- The influence of thixotropy on the formwork pressure was evaluated.

- Four thixotropy determination test methods were compared.

- New models were developed to estimate formwork pressure of SCC.

- Thixotropy and time is the functions of the models.

\section{A R T I C L E I N F O}

\section{Article history:}

Received 15 March 2017

Received in revised form 27 March 2018

Accepted 5 April 2018

Available online 24 April 2018

\section{Keywords:}

Self-consolidating concrete

Thixotropy methods

Formwork pressure

\begin{abstract}
A B S T R A C T
In this experimental study, the influence of thixotropy determined by different test methods on the formwork pressure of self-consolidating concrete (SCC) with varying compositions was investigated. In order to determine the effect of water/binder $(\mathrm{w} / \mathrm{b})$ ratio, slump flow diameter and coarse aggregate/total aggregate (CA/TA) ratio on thixotropy and formwork pressure of SCC, fifteen concrete mixtures were prepared. Four different test methods i.e., "structural break-down area" (SBDA), "break-down percentage" (BDP), "drop in apparent viscosity" (DAV) and "yield value at rest" (YVR) were performed to determine the thixotropy of the SCC mixtures. Test results showed that the SBDA, DAV and YVR methods were more appropriate to evaluate the thixotropy of SCC than the BDP method. A strong correlation between thixotropy and formwork pressure was found using SBDA, DAV and YVR methods in SCC mixtures having low $\mathrm{w} / \mathrm{b}$ ratio. There was a strong relationship between thixotropy determined by SBDA, BDP and DAV methods and formwork pressure in low slump flow SCC mixtures, while thixotropy determined by the YVR method showed good correlation with the formwork pressure in SCC mixtures having high slump flow values. Finally, new models were developed to estimate the formwork pressure of all kinds of mixtures as a function of thixotropy and time. The models were found to be successful for each of the thixotropy measurement method.
\end{abstract}

(c) 2018 Elsevier Ltd. All rights reserved.

\section{Introduction}

Self-consolidating concrete (SCC) can fill in the formwork completely without vibration requirement for placing and compaction [1]. The fluid consistency and high cohesiveness of SCC makes it easier to fill the formworks densely. SCC can provide shorter construction period, less labor costs and lower noise level during casting operations. Hardened SCC has lower permeability and

\footnotetext{
* Corresponding author.

E-mail address: murat.tuyan@ege.edu.tr (M. Tuyan).
}

better mechanical and durability performance than the conventional concrete [2-4]. However, the higher amount of binder and chemical admixtures in SCC than those in conventional concrete is the major disadvantage of SCC in terms of concrete cost [5]. In addition, its high pressure applied on formwork on site is another disadvantage [6].

Thixotropy is the property of decreasing viscosity under a constant shear stress or shear rate in time and returning the initial state gradually when the shear stress or shear rate effect is removed [7]. Thixotropy of the concrete is mainly affected by the properties of concrete constituents and mix proportions such as 
the chemical composition, fineness, and the setting time of the cement, water/cement (w/c) ratio, amount of fine or coarse aggregate, type and dosage of chemical admixtures as well as mixing and vibration processes. In order to investigate the effect of $w / c$ ratio on SCC thixotropy, Khayat and Assaad [8] prepared three different SCC mixtures with w/c ratios of $0.36,0.40$ and 0.46 . The lowest initial and equilibrium torque values were obtained in the mixture having $\mathrm{w} / \mathrm{c}$ ratio of 0.46 . The thixotropy was reported to decrease upon increasing $\mathrm{w} / \mathrm{c}$ ratio. This was mainly attributed to the decreased superplasticizer demand of the mixtures having high w/c ratio. Assaad et al. [9] observed the effect of mineral admixtures on the thixotropy of SCC mixtures. The SCC mixture having $4 \%$ silica fume in the cement showed lower thixotropic behavior than the SCC mixture having binary replacement of $4 \%$ silica fume and $22 \%$ fly ash by weight of cement. With the use of $22 \%$ fly ash which was finer than the portland cement, the fineness of the binder increased and this promoted the interaction between the cement particles, resulting in an increase in the thixotropy of the SCC mixture. Assaad [10] examined the effects of the consistency and temperature of the concrete during casting on thixotropy of SCC mixture. Three different SCC mixtures with slump flow values of $550 \mathrm{~mm}, 650 \mathrm{~mm}$ and $750 \mathrm{~mm}$ as well as a conventional concrete mixture with the slump value of $220 \mathrm{~mm}$ were prepared. It was observed that the yield stress, thus the initial torque, of SCC mixtures with low slump flow values were higher than those of the mixtures with high slump flow. As the mixtures with lower slump values included less superplasticizer, there was higher interaction between the particles. In order to investigate the effect of temperature on thixotropy, SCC mixtures were prepared at 10 ${ }^{\circ} \mathrm{C}, 20^{\circ} \mathrm{C}$, and $30^{\circ} \mathrm{C}$. Test results indicated that the higher the temperature of the concrete, the higher the thixotropy. The rise of temperature increased the rate of hydration of the cement resulting in an increase in higher yield stress and initial torque value of the concrete mixture.

In the reinforced concrete constructions, the cost of the formwork constitutes $40 \%$ to $60 \%$ of the concrete cost [11]. In order to reduce the formwork cost, the long standing method of reducing the lateral formwork pressure has been used. There has been a great number of laboratory and field work to determine the effects of fresh concrete characteristics on formwork pressure $[6,8,10]$. Formwork pressure becomes more important as the height increases, which forces the researchers to take measurements in the field or to mimic similar conditions in the laboratory [12]. Various methods have been developed in the laboratory in order to measure formwork pressure for excessive heights. For example, in some studies, SCC mixture was placed into the formwork and compressed air is applied onto the SCC mixture [13,14]. In some others, SCC mixture was placed into $150 \times 300 \mathrm{~mm}$ cylindrical molds and pressure is applied with a hydraulic pressure on the surface of the SCC mixture [15].

Fresh SCC can be considered as a suspension with solid particles or as a liquid with high viscosity. This leads to an approximation of hydrostatic pressure for calculating the formwork pressure, which results in an overestimation of the actual pressures [10] and leads to overdesign and cost for the formworks. CEBTP [16] indicated that the pressure of SCC which was cast in a 12-meter-high formwork is $35 \%$ less than the hydrostatic pressure at the bottom of the formwork. Ovarlez and Roussel [17] stated that when the thixotropy is high and the casting rate is low, concrete starts to behave as a solid rather than a liquid and as a result, its lateral formwork pressure is lower than the hydrostatic pressure. In addition, as it is supposed that the formwork pressure of SCC is higher than that of the traditional concrete, the placing height (or lift) of fresh SCC mixture is also limited $[17,18]$. The most comprehensive studies on the effects of SCC on lateral formwork pressure were started in 2001 by Khayat and Assaad. In these studies, it was found that an increase in the volume of coarse aggregate [10], a decrease in $\mathrm{w} / \mathrm{c}$ ratio [8] and the amount of binder [19,20], and using mineral admixtures (silica fume, fly ash, and ground granulated blast furnace slag) [10] decreased the formwork pressure. The decrease in formwork pressure in time increases by the increase in the amount of binder [19,20], water/cement ratio [8] and temperature of SCC [21], as well as a decrease in the superplasticizer demand [8], presence of viscosity modifying and set accelerating admixtures $[22,23]$ and the reduction of consistency [10]. The general conclusion of the studies made by Assaad et al. [9] and Assaad [10] reveals that the increase in the thixotropy of SCC decreases both the maximum lateral formwork pressure of SCC after the initial casting and the lateral pressure drop with time.

Attempts have been made in several studies [17,24-35] to model the SCC formwork pressure in the laboratory and a number of experts representing these models gathered in Stockholm, Sweden to carry out a field evaluation [36]. Eight instrumented wall elements were cast with SCC using different mix designs as well as various casting rates. The predicted formwork pressures were compared with the actual values. The models were found to predict the lateral form pressure satisfactorily. The regression coefficients $\left(R^{2}\right)$ for the methods ranged between 0.69 and 0.86 [36].

In this study, it is aimed to compare the different test methods for determination of thixotropy and to evaluate the effect of mix design parameters $(\mathrm{w} / \mathrm{b}$ ratio, slump flow diameter and coarse aggregate/total aggregate ratio) on thixotropy and formwork pressure of SCC mixtures. For this purpose, fifteen SCC mixtures were prepared and four different test methods were used for determining thixotropy. Then, the influence of thixotropy on the formwork pressure was evaluated.

Another object of the study was to propose new models to predict the SCC formwork pressures. The new models were based on the model given in $[25,29]$. Different from that model, the thixotropy values obtained from different methods were included in the new models.

\section{Materials and methods}

2.1. Materials

In this study, a CEM I $42.5 \mathrm{R}$ type cement and a Type F fly ash were used as binders. Physical and chemical properties of the binders are given in Table 1 .

A crushed limestone aggregate of two different size fractions (0-4 $\mathrm{mm}$ and 4$16 \mathrm{~mm}$ ) was used in the concrete production. Sieve analysis of the fine and coarse aggregate is given in Table 2 . The saturated surface dry specific gravity values of fine and coarse aggregate, determined in accordance with EN 1097-6 [37], were 2.61 and 2.64, respectively. Water absorption capacity of the fine and coarse aggregate [37] was found to be $0.67 \%$ and $0.21 \%$, respectively. A polycarboxylic ether based high range water reducing admixture (HRWR) having a specific gravity of 1.10 was used.

Table 1

Chemical composition and some physical properties of the binders.

\begin{tabular}{lll}
\hline Composition (\%) & Portland cement & Fly ash \\
\hline $\mathrm{SiO}_{2}$ & 21.72 & 56.20 \\
$\mathrm{Al}_{2} \mathrm{O}_{3}$ & 5.96 & 25.34 \\
$\mathrm{Fe}_{2} \mathrm{O}_{3}$ & 3.60 & 7.65 \\
$\mathrm{CaO}$ & 60.78 & 1.64 \\
$\mathrm{MgO}$ & 2.64 & 1.80 \\
$\mathrm{~K}_{2} \mathrm{O}$ & 0.75 & 1.88 \\
$\mathrm{Na}_{2} \mathrm{O}$ & 0.17 & 1.13 \\
$\mathrm{SO}_{3}$ & 2.17 & 0.32 \\
Loss on ignition & 2.01 & 2.10 \\
Specific gravity & 3.07 & 2.31 \\
Initial setting time (min.) & 70 & - \\
Final setting time (min.) & 205 & - \\
\hline
\end{tabular}


Table 2

Sieve analysis of fine and coarse aggregate.

\begin{tabular}{lll}
\hline Sieve size, $(\mathrm{mm})$ & Passing, $(\%)$ & \\
\cline { 2 - 3 } & $0-4 \mathrm{~mm}$ & $4-16 \mathrm{~mm}$ \\
\hline 16 & 100 & 100 \\
8 & 100 & 42 \\
4 & 100 & 2 \\
2 & 75 & 0 \\
1 & 53 & 0 \\
0.5 & 27 & 0 \\
0.25 & 14 & 0 \\
\hline
\end{tabular}

\subsection{Preparation of SCC mixtures}

In order to determine the thixotropy and formwork pressure, mixtures having three different $\mathrm{w} / \mathrm{b}$ ratios $(0.35,0.42$ and 0.50$)$ were prepared with three different target slump flow diameter values (550, 650 and $720 \pm 20 \mathrm{~mm}$ ). Besides, for a constant slump flow diameter of $650 \mathrm{~mm}$, a series of mixtures with CA/TA ratios (by mass) of $0.45,0.50$ and 0.53 were prepared. The cement $\left(415 \pm 4 \mathrm{~kg} / \mathrm{m}^{3}\right)$ and fly ash $\left(125 \mathrm{~kg} / \mathrm{m}^{3}\right)$ contents of all mixtures were kept constant. The amount of HRWR was determined by trial and error to obtain target slump flow diameter values. Mixture proportions of 15 different SCC mixtures are given in Table 3. The mixtures are designated by $\mathrm{w} / \mathrm{b}$ ratio (in percent)/CA-to-TA ratio (in percent)/and slump flow diameter (in $\mathrm{cm}$ ), respectively. For example, 35/50/65 denotes the mixture having $0.35 \mathrm{w} / \mathrm{b}$ ratio, $0.50 \mathrm{CA} / \mathrm{TA}$ ratio and $650 \mathrm{~mm}$ slump flow.

Coarse and fine aggregate were mixed in the mixer with one third of the mixing water. Portland cement and fly ash were then introduced into the mixer and mixed with the rest of water containing HRWR. The total mixing operation continued for eight minutes then the slump flow was measured in accordance with EFNARC guideline [1].

\subsection{Determination of thixotropy}

The thixotropy tests were conducted by using ConTec 4SCC rheometer equipped with modified Tattersall type impeller. The thixotropy tests were conducted immediately after the preparation of the SCC mixtures, and repeated at 90 and $150 \mathrm{~min}$ after mixing. Thixotropy of SCC mixtures was determined by four different methods; i.e. "structural break-down area" (SDBA) method [38], "break-down percentage" (BDP) method [39], "drop in apparent viscosity" (DAV) method [10] and "yield value at rest" (YVR) method [40].

In accordance with the SDBA method proposed by Lapasin et al. [38], the fresh SCC mixture was placed into the rheometer container, left at rest for $5 \mathrm{~min}$ and exposed to shear at a constant rotational speed of $0.2 \mathrm{rps}$. After a 5 -min rest, the concrete mixtures were exposed to shear at speeds of $0.4,0.6$, and $0.8 \mathrm{rps}$. The shear duration for each speed was $10 \mathrm{~s}$. These speeds and the shear duration were determined according to the rheometer capacity and the other studies in the literature $[8,9,19]$. Although the mixtures reached to the equilibrium state within about six seconds, for the reliability of the results, the durations were extended to $10 \mathrm{~s}$ for each speed value. An example data set obtained from the sample (w/b: $0.35, \mathrm{CA} /$ TA: 0.50 , slump flow: $650 \mathrm{~mm}$ ), which was tested with this method, can be seen in Fig. 1. For each speed, time-dependent changes in torque were observed and initial as well as equilibrium torque values were determined. The equilibrium torque values are the average of twelve values belonging to the last three seconds (the rheometer records four torque values per second). The torque values thus determined were plotted against rotational speed values as shown in Fig. 2. For these points, a second-degree polynomial trend line was fitted in order to find an equation. The correlation coefficient was found to be higher than 0.90 for all SCC mixtures. Then, the area between the two curves was calculated by integration of the equations and was identified as the structural break-down area.

In accordance with the BDP method proposed by Lin [39], the data taken for the SDBA method were used. The initial torque and equilibrium torque values for 0.4 rps speed were considered (Fig. 2). The difference between these values was divided by the equilibrium values and the results were expressed in percentages, as shown below.

Break - down percentage $=\frac{\text { initial torque }- \text { equilibrium torque }}{\text { equilibrium torque }} \times 100$

In the DAV method proposed by Assaad [10], the data taken for the SDBA method were used. However, the difference between initial and equilibrium values for 0.4 rps speed was divided by the rotational speed $(0.4 \mathrm{rps})$.

Dropinapparent viscosity $=\frac{\text { initial torque }- \text { equilibrium torque }}{\text { rotational speed }}$

In the YVR method proposed by Dzuy et al. [40], fresh SCC mixtures were exposed to shear at a very low constant speed ( $0.03 \mathrm{rps})$ after a 5 -min rest. During the tests, time-dependent changes in torque values were recorded. The maximum

늠 놏

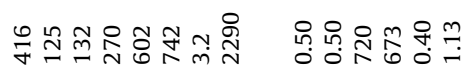

응

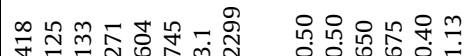

足

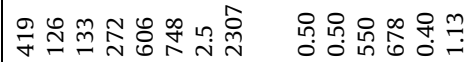

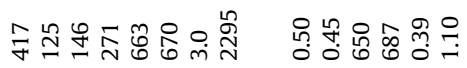

党

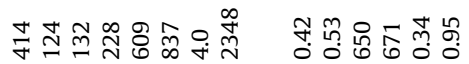

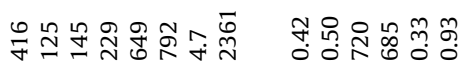

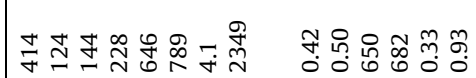

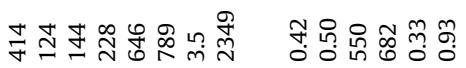

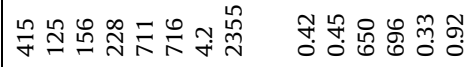

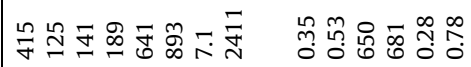

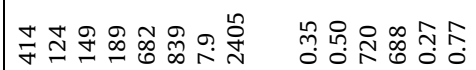

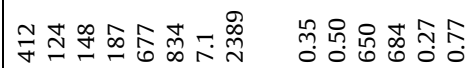

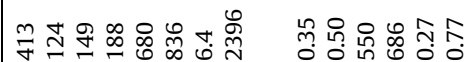

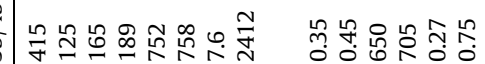




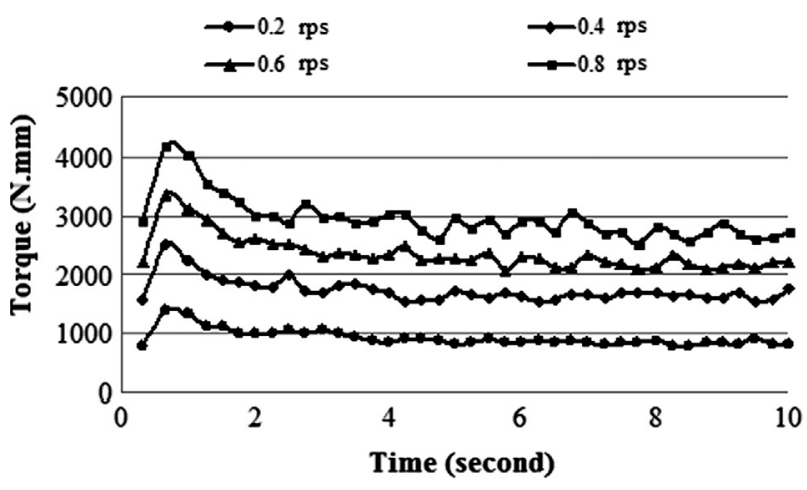

Fig. 1. Time-dependent change in torque at four different rotational speeds.

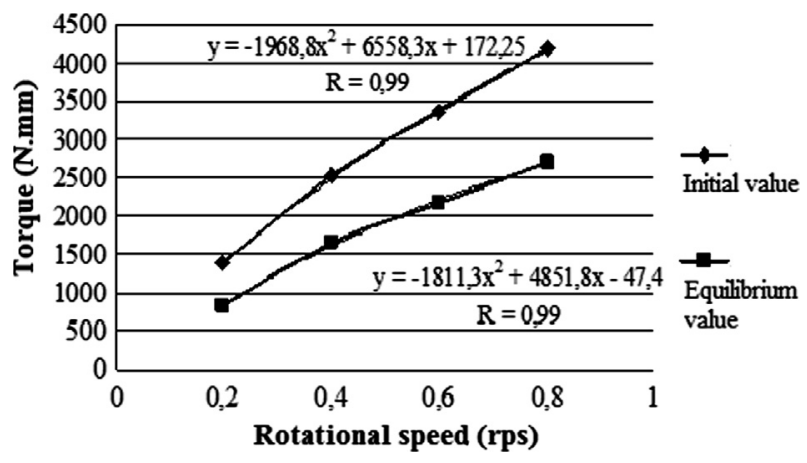

Fig. 2. Calculation of structural break-down area.

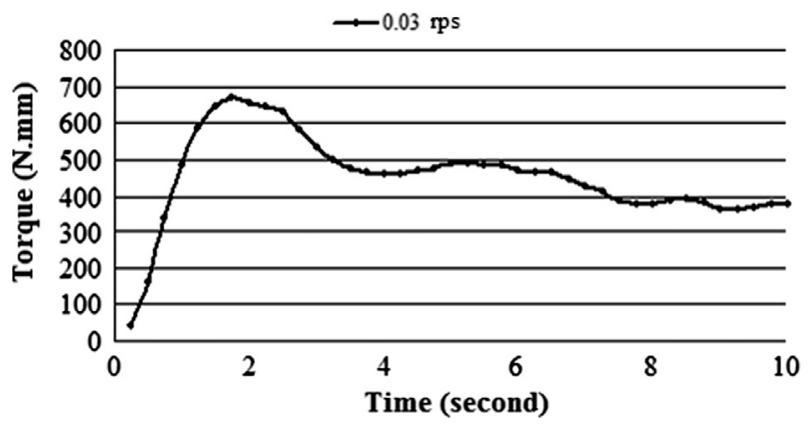

Fig. 3. Time-dependent change in torque for YVR.

torque value was taken as YVR. For example, the torque-time relation of 35/50/65 mixture exposed to 0.03 rps shear speed is shown in Fig. 3.

\subsection{Determination of formwork pressure}

During thixotropy tests, formwork pressure was also measured simultaneously. For this measurement, a steel pressure formwork ( $200 \times 200 \mathrm{~mm}$ square cross section and $700 \mathrm{~mm}$ height) with an airtight lid on top was used (Fig. 4). The pressure was measured by pressure sensors which transferred the data to a computer via a data acquisition device. The sensors were placed at the heights of $50 \mathrm{~mm}, 200 \mathrm{~mm}$ and $350 \mathrm{~mm}$ above the bottom. The fresh concrete mixtures were cast into the formwork at a rate of $5 \mathrm{~m} / \mathrm{h}$. Meanwhile, the sensors started to record the pressure data. As the level of the concrete reached $500 \mathrm{~mm}$, the lid was closed rapidly. In order to increase the pressure to the desired level, additional pressure was applied into the formwork by means of an air compressor securing the same casting rate. The formwork pressure was kept constant further when the bottom pressure was equivalent to the pressure of fresh SCC with $10 \mathrm{~m}$ height. This pressure level was calculated by considering the density of each mixture. The measurements continued for 4-8 h, depending on the setting time of SCC mixtures, determined in accordance with ASTM C403 [41]. The tests were ended before the initial setting time, in order to protect the sensors from damage during the removal of the concrete from the formwork. In order to see the effect of casting rate, the same procedure was repeated at the casting rate of $10 \mathrm{~m} / \mathrm{h}$. Fig. 5 shows a graph of formwork pressure measurements by using 35/50/65 mixture cast at a rate of $10 \mathrm{~m} / \mathrm{h}$.

\section{Test results and discussion}

\subsection{Thixotropy of SCC mixtures}

3.1.1. Effect of $w / b$ ratio and slump flow on thixotropy of SCC mixtures

The results obtained by the SDBA method (Fig. 6(a)) showed that for a given $\mathrm{w} / \mathrm{b}$ ratio, thixotropy of the mixtures decreased with an increase in slump flow diameter. The use of more superplasticizer to increase the slump flow diameter caused the dispersion of the particles and weakened the structural interactions between cement particles. Thixotropy values of the mixture having $\mathrm{w} / \mathrm{b}$ ratio of 0.35 decreased $48 \%$ due to the increase in slump flow diameter from $550 \mathrm{~mm}$ to $650 \mathrm{~mm}$, while, there was not a significant decrease with increasing slump flow diameter from $650 \mathrm{~mm}$ to $720 \mathrm{~mm}$. On the other hand, the decrease in thixotropy was not prominent in the mixtures having $\mathrm{w} / \mathrm{b}$ ratio of 0.42 and 0.50 which required relatively low superplasticizer amounts. Fig. 6(a) also shows that thixotropy values of the mixtures decreased as the $\mathrm{w} / \mathrm{b}$ ratio increased. This seems to be arisen from the dispersion of cement particles by the superplasticizer. Khayat and Assaad [7] indicated that higher water content and relatively lower coarse aggregate volume have predominant influence on lowering the degree of thixotropy.

As seen from Fig. 6(c) and (d), similar results were obtained by using DAV and YVR methods, indicating a decrease in thixotropy upon increasing $\mathrm{w} / \mathrm{b}$ ratio and slump flow diameter. However, the results of the BDP method were contrary to the other methods mentioned above, indicating that BDP method is not as reliable as the others for determining the thixotropy of SCC mixtures.

\subsubsection{Effect of CA/TA ratio on thixotropy of SCC mixtures}

The effect of CA/TA ratio on thixotropy was more pronounced in the mixtures having low $\mathrm{w} / \mathrm{b}$ ratio (0.35) (Fig. 7). SCC mixtures having $\mathrm{w} / \mathrm{b}$ ratio of 0.50 had the lowest thixotropy value and the thixotropy was not affected by the changes in CA/TA ratio. Moreover, recalling the Fig. 6(a), (c) and (d), thixotropy of the SCC mixtures having $\mathrm{w} / \mathrm{b}$ ratio of 0.50 was less affected by the changes in slump flow diameter. On this basis, it can be said that a high $\mathrm{w} / \mathrm{b}$ ratio of SCC mixtures discouraged the formation of interactions in the concrete mixtures, reducing the contribution of other parameters (i.e. slump flow and CA/TA ratio) on thixotropy. As Fig. 7 shows, an increase in thixotropy value was observed with an increase in CA/TA ratio in the mixture with $\mathrm{w} / \mathrm{b}$ ratio of 0.35 . In addition, except for BDP method (Fig. 7(b), a significant increase in thixotropy was observed with increasing CA/TA ratio from 0.50 to 0.53 . This is due to the fact that the high amount of coarse aggregate increased internal friction in the concrete mixture. Similar results were reported by Assaad [10]. For the SCC mixtures having $\mathrm{w} / \mathrm{b}$ ratio of 0.42 , different thixotropy determination methods generated different test results. However, an increase in thixotropy value was expected with an increase in CA/TA ratio. SDBA and BDP methods provided this phenomenon.

\subsubsection{The change in thixotropy with time}

Fig. 8 shows the change in thixotropy of the mixtures having $\mathrm{w} /$ b ratio of 0.35 and CA/TA ratio of 0.50 with time. Normally, thixotropy is expected to increase due to consumption of water during hydration. The SDBA and BDP method did not clearly indicate significant change in thixotropy with time. Furthermore, the thixotropy determined by BDP method did not vary a lot with time for the mixtures having different slump flow values (Fig. 8 (b)). When DAV method was used, thixotropy increased with time for the slump flow values of $550 \mathrm{~mm}$ and $650 \mathrm{~mm}$ while it decreased for the $720 \mathrm{~mm}$ slump flow Fig. 8(c). In general, as can be observed from Fig. 8(a-c), depending on the method applied and the mix- 

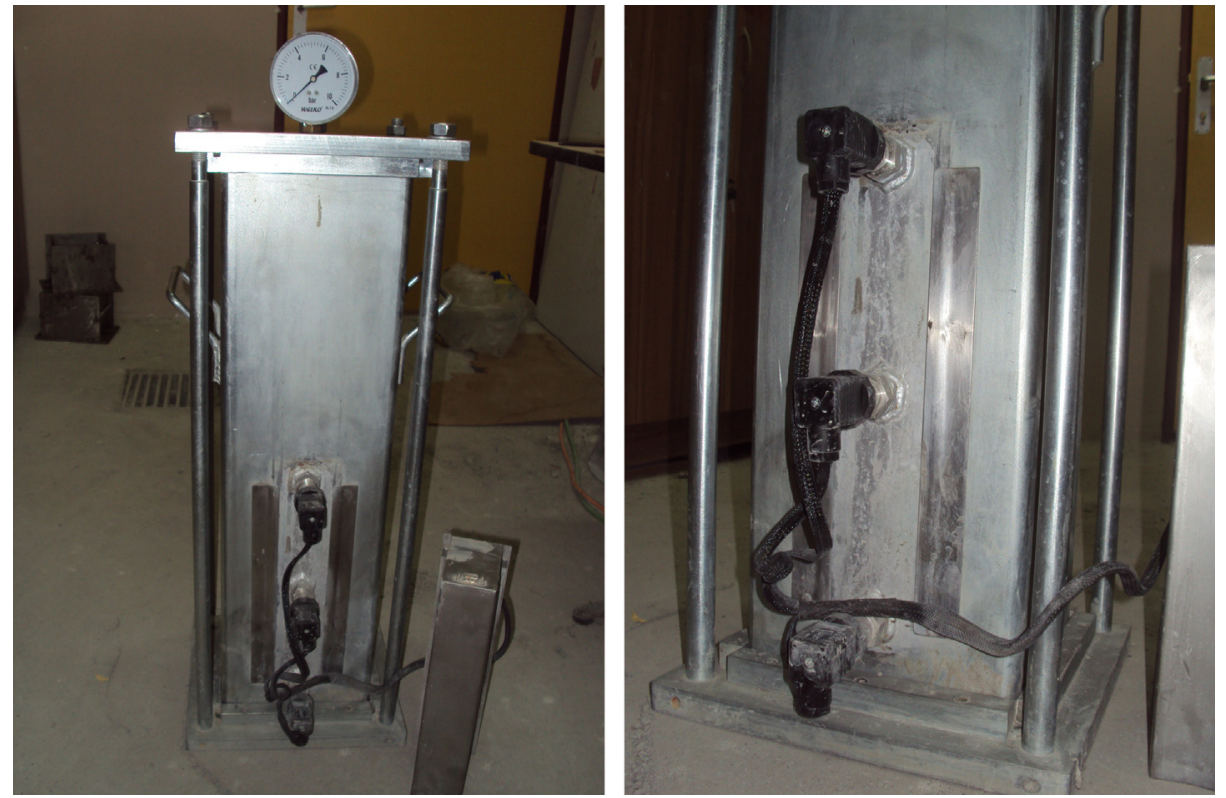

Fig. 4. Steel pressure formwork.

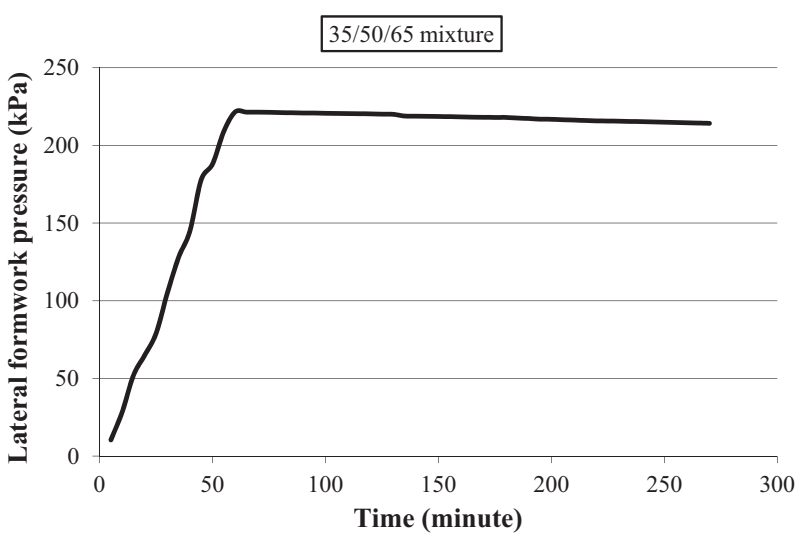

Fig. 5. Time-dependent change in lateral formwork pressure for 35/50/65 mixture.

ture, thixotropy increased with time in some mixtures, whereas it decreased with time in the others. In SDBA, BDP and DAV methods, the thixotropy calculations are based on the difference between the initial and equilibrium torque values. Since the difference between them did not necessarily increase with time, these methods were found to be inappropriate to follow the change in thixotropy with time. In YVR method, on the other hand, the thixotropy values increased with time for almost all of the mixtures as expected. It was observed that the mixture having the highest superplasticizer content (or slump flow) did not develop an increase in thixotropy even after $150 \mathrm{~min}$. This may be arisen from the set-retarding effect of the superplasticizer and its relatively high content in these SCC mixtures.

\subsection{Effect of mixture proportions and casting rate of SCC mixtures on} formwork pressure

\subsubsection{Effect of $w / b$ ratio on formwork pressure of SCC mixtures}

The time-dependent drop in the formwork pressure of SCC mixtures with the slump flow diameter of $550 \mathrm{~mm}$ and different $\mathrm{w} / \mathrm{b}$ ratios is shown in Fig. 9(a). In the mixtures having $w / b$ ratio of 0.50 , drop in the formwork pressure was observed to be the slow- est. This shows that the gradual drop in the pressure becomes slower when $\mathrm{w} / \mathrm{b}$ ratio increases. This is because the water content in the mixture increases as $\mathrm{w} / \mathrm{b}$ ratio rises and the increasing pore water pressure affects the formwork pressure. As it can be seen from Fig. 9(b), the formwork pressure caused by the mixture having $\mathrm{w} / \mathrm{b}$ ratio of 0.50 was higher than those of mixtures having $\mathrm{w} / \mathrm{b}$ ratio of 0.35 and 0.42 within the first $200 \mathrm{~min}$. After $200 \mathrm{~min}$, the formwork pressure caused by the mixtures with 0.50 and 0.42 $\mathrm{w} / \mathrm{b}$ ratios decreased more rapidly. Upon increasing the slump flow value to $720 \mathrm{~mm}$, all of the mixtures behaved similarly from formwork pressure view point (Fig. 9(c)). In a similar manner, the effect of $w / b$ ratio on the thixotropy of the mixtures became less evident upon increasing slump flow of the mixture (Fig. 6). Moreover, as it can be seen from Fig. 9, as slump flow rises in SCC mixtures, the effects of a change in $\mathrm{w} / \mathrm{b}$ ratio become less visible on formwork pressure. The main reason of this is that as slump flow of a mixture with low $\mathrm{w} / \mathrm{b}$ ratio increases, the superplasticizer requirement also increases.

\subsubsection{Effect of slump flow of SCC mixtures on formwork pressure}

The time-dependent changes in the formwork pressure of concrete mixtures with $\mathrm{w} / \mathrm{b}$ ratio of 0.35 and different slump flow diameters are shown in Fig. 10(a). Within the first $100 \mathrm{~min}$, the fall in the formwork pressure of the mixture with $720 \mathrm{~mm}$ slump flow was about $10 \%$, whereas, that of mixture with $550 \mathrm{~mm}$ slump flow was about $50 \%$. As the slump flow of the mixture increased, the fall in the formwork pressure decreased with time. This is because a higher slump flow decreases thixotropy (Fig. 6(a)). In other words, a decrease in thixotropy slows down the fall in pressure. In Fig. 10 (b), the time-dependent change in the formwork pressure of concrete mixtures with $\mathrm{w} / \mathrm{b}$ ratio of 0.42 and different slump flows is shown. As the slump flow diameter of the mixture increased, the drop in the formwork pressure decreased with time. Within the first $100 \mathrm{~min}$, the drop in the formwork pressure of the mixture with slump flow diameter of $550 \mathrm{~mm}$ was about $70 \%$, whereas that of the mixture with slump flow diameter of $720 \mathrm{~mm}$ was $87 \%$. This is due to a decrease in the amount of superplasticizer and an increase in the amount of water and pore water pressure. In Fig. 10(c), the time-dependent change in the formwork pressure of concrete mixtures with $\mathrm{w} / \mathrm{b}$ ratio of 0.50 and different slump flows is shown. As the slump flow of a mixture increased, the fall 


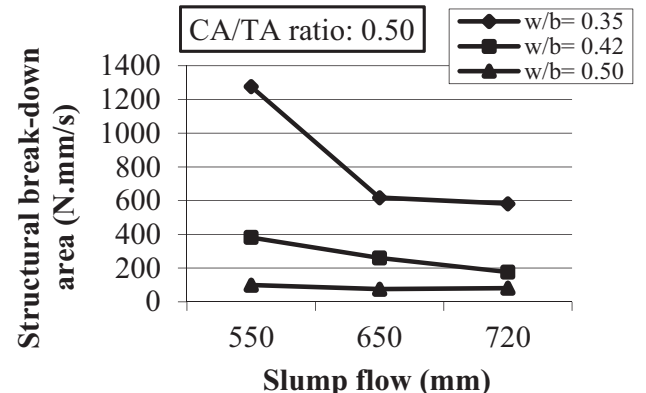

(a)

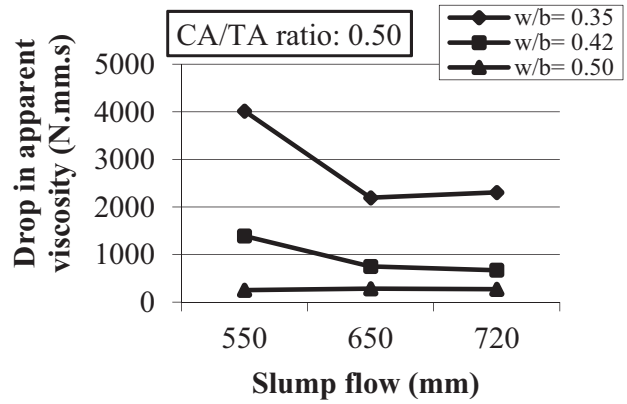

(c)

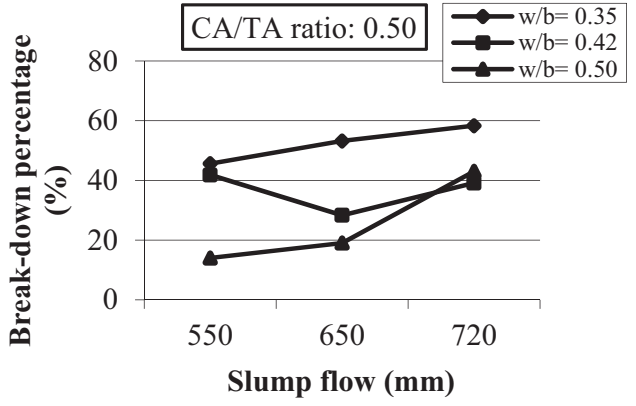

(b)

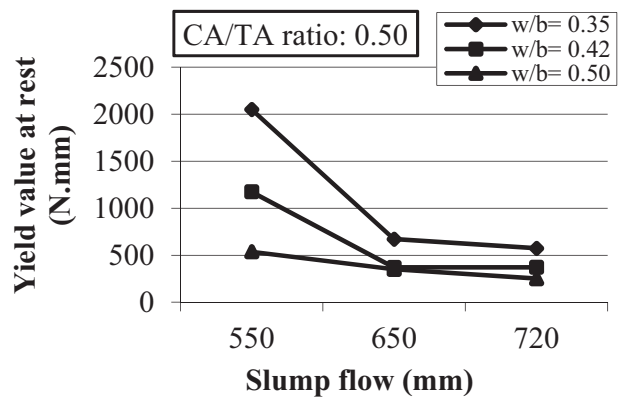

(d)

Fig. 6. The relationship between thixotropy and slump flow diameter of SCC mixtures with different w/b ratios.

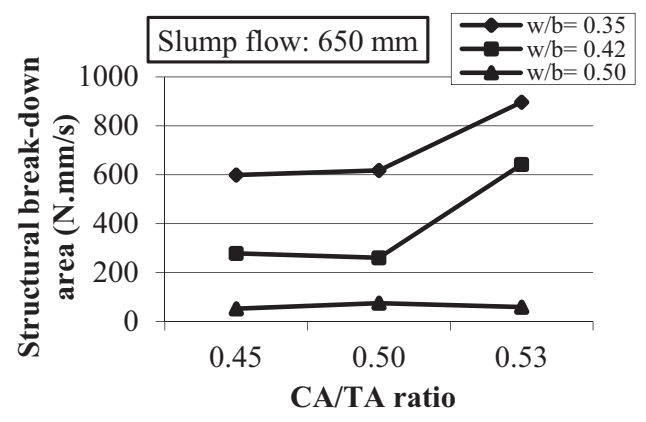

(a)

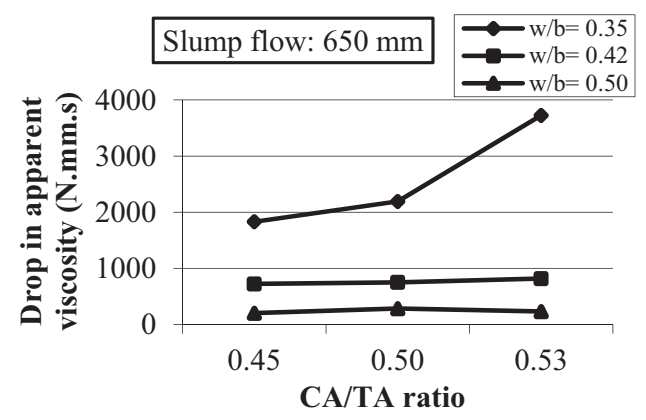

(c)

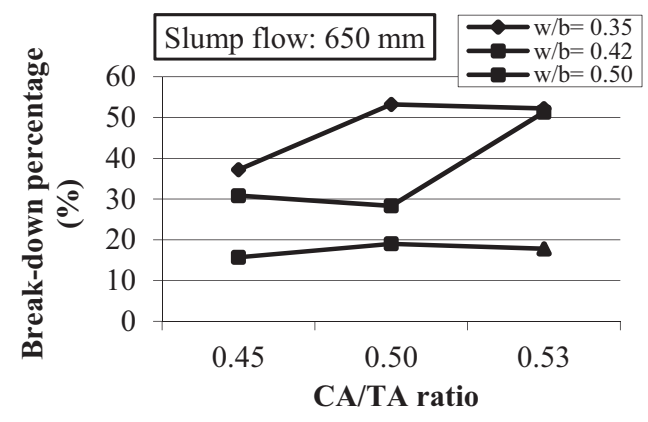

(b)

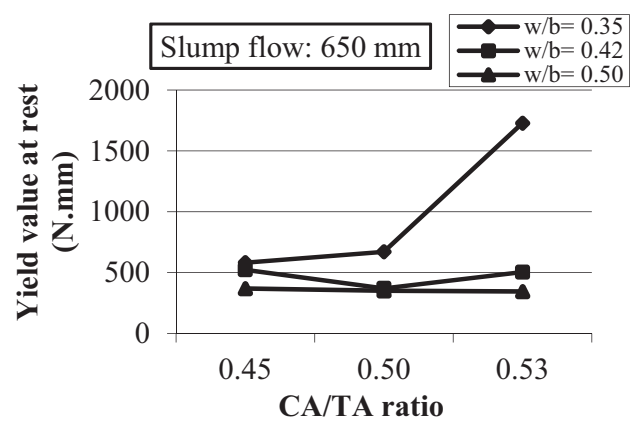

(d)

Fig. 7. The relationship between thixotropy and CA/TA ratio of SCC mixtures with different w/b ratios.

in the formwork pressure decreased with time. It is clear that in the mixtures having higher $\mathrm{w} / \mathrm{b}$ ratios the effect of slump flow diameter on the formwork pressure is less pronounced. This can be explained by examining Fig. 7(a). When w/b ratio increases, changes in slump flow become less effective on thixotropy and formwork pressure.
3.2.3. Effect of $C A / T A$ ratio of SCC mixtures on formwork pressure

In Fig. 11(a), the effect of CA/TA ratio on the formwork pressure of concrete mixtures with $\mathrm{w} / \mathrm{b}$ ratio of 0.35 is shown. Compared to the mixtures with CA/TA ratios of 0.50 and 0.53 , the one with $\mathrm{CA} /$ TA ratio of 0.45 caused a slower fall in the formwork pressure. In spite of having constant water content, when the amount of coarse 


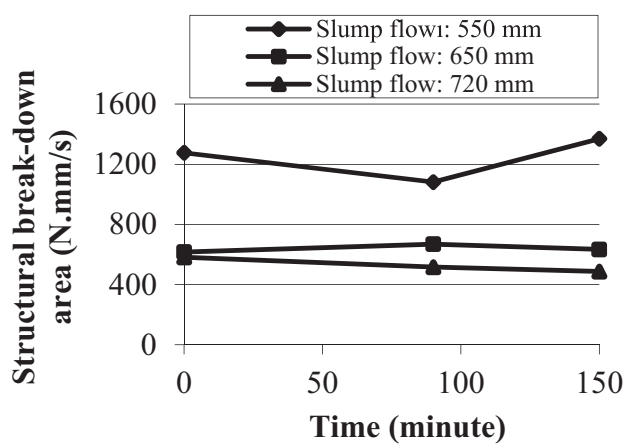

(a)

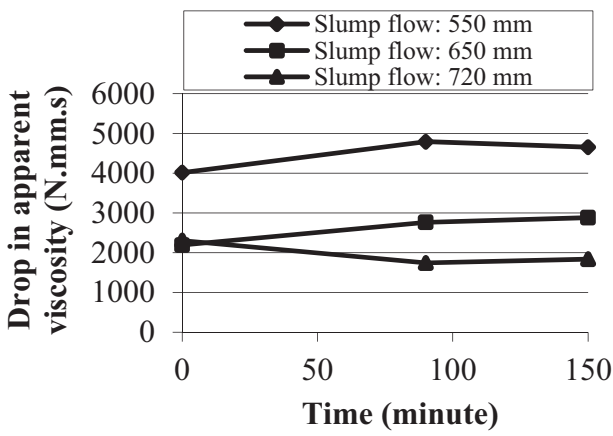

(c)

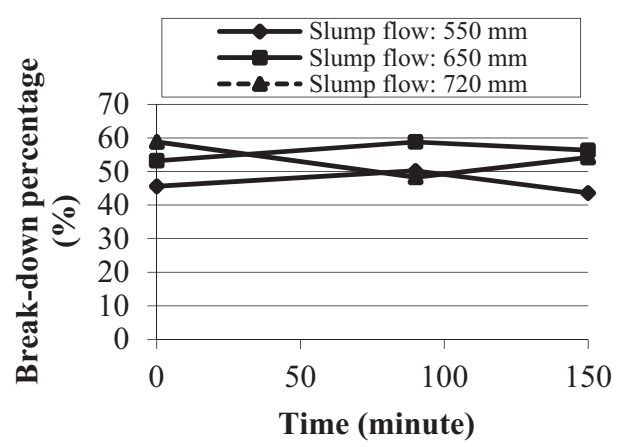

(b)

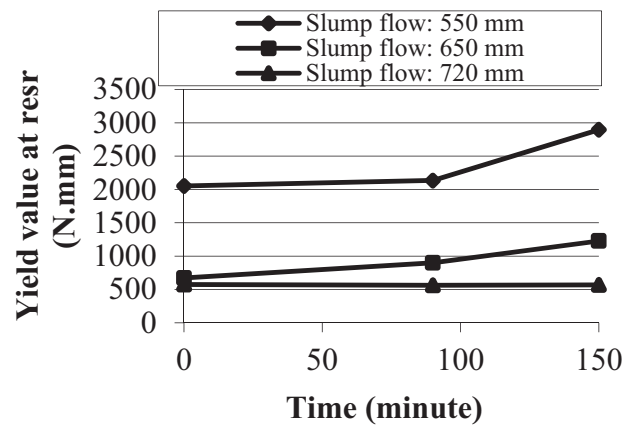

(d)

Fig. 8. The change in thixotropy in time which was measured with four different thixotropy methods $(w / b=0.35$ and $C A / T A=0.50)$.

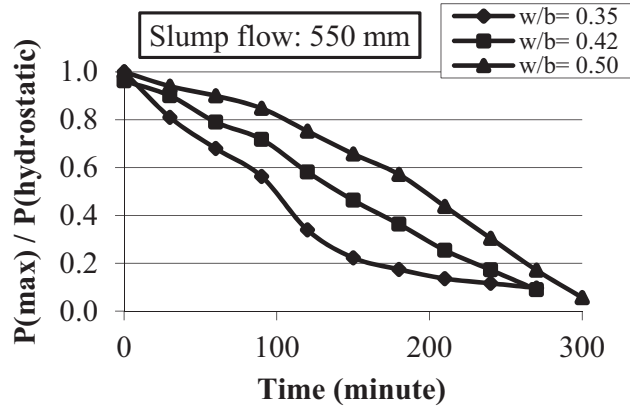

(a)

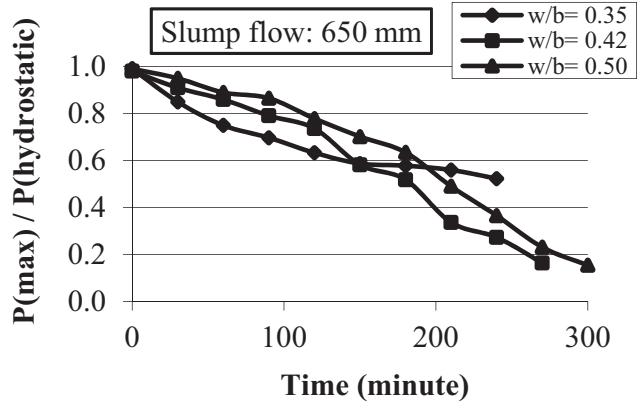

(b)

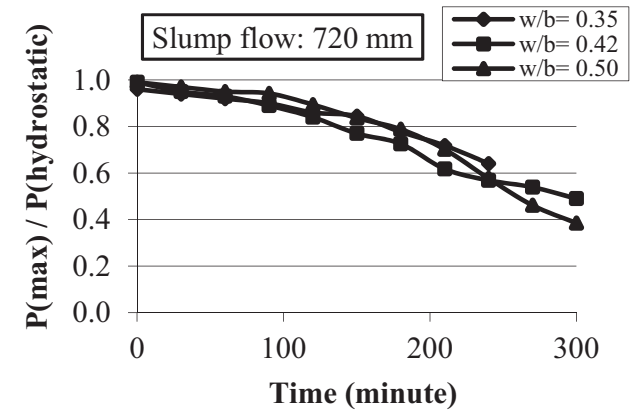

(c)

Fig. 9. The time-dependent drop in the formwork pressure of SCC mixtures with different slump flow diameters.

aggregate in the mixtures increased, the formwork pressure decreased. This is because of an increase in thixotropy as a result of an increase in CA/TA ratio in a mixture with $0.35 \mathrm{w} / \mathrm{b}$ ratio
(Fig. 6(a)). In Fig. 11(b), a gradual change in formwork pressure caused by a change in CA/TA ratio (for w/b ratio of 0.42 ) is shown. In general, the mixture with CA/TA ratio of 0.53 exerted the lowest 


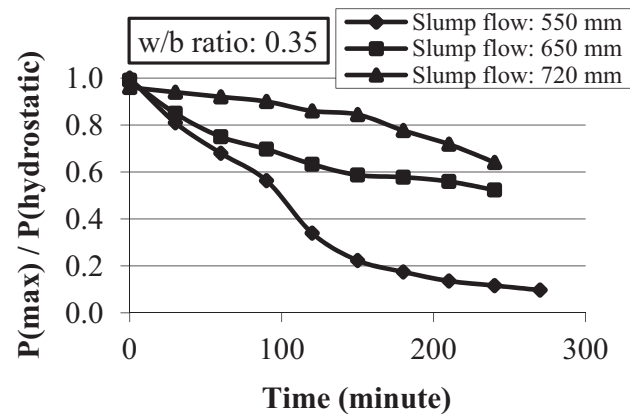

(a)

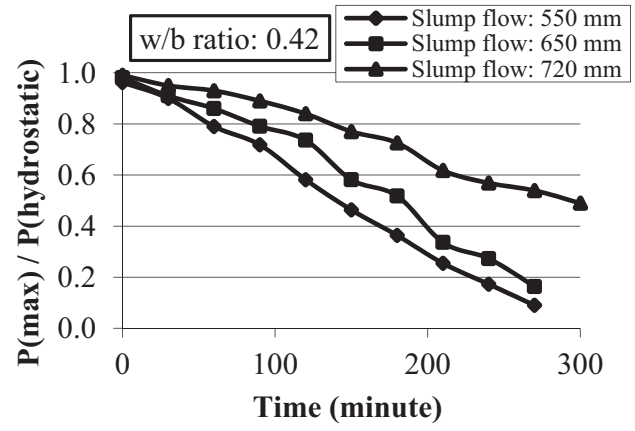

(b)

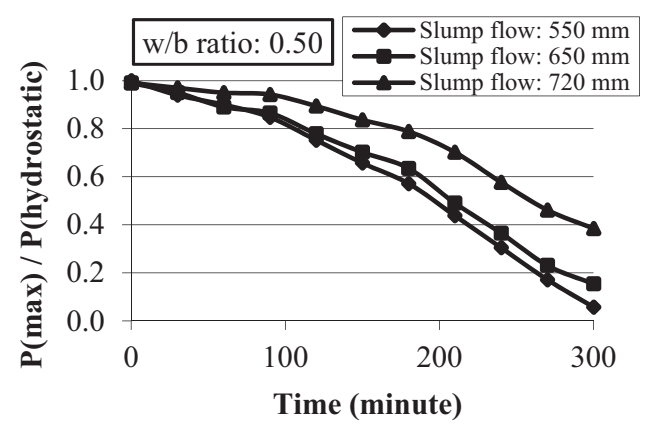

(c)

Fig. 10. The time-dependent drop in the formwork pressure of SCC mixtures with different w/b ratios.

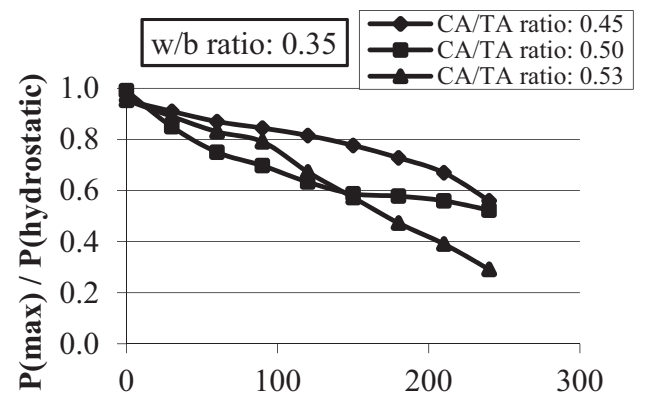

Time (minute)

(a)

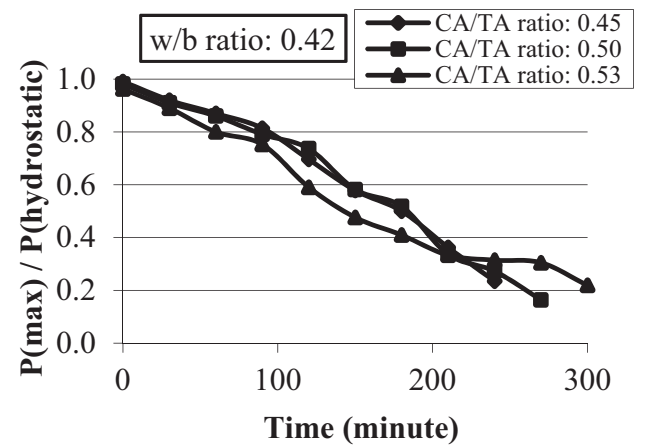

(b)

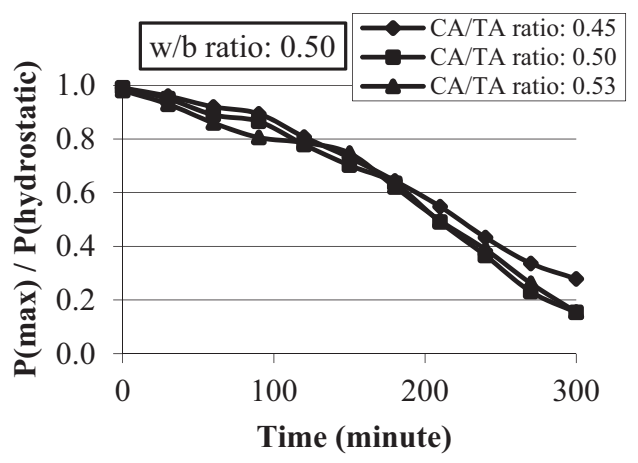

(c)

Fig. 11. The time-dependent drop in the formwork pressure of SCC mixtures with different CA/TA ratios. 
formwork pressure. The formwork pressure of the mixtures having CA/TA ratio of 0.45 and 0.50 are very close to each other. A gradual reduction in formwork pressure caused by the change in CA/TA ratio for the mixtures with $0.50 \mathrm{w} / \mathrm{b}$ ratio was observed (Fig. 11 (c)). In these mixtures, the change in CA/TA ratio did not cause a drastic change in the formwork pressure of fresh concrete. Similarly it is obvious from Fig. 7(a) that an increase in CA/TA ratio of the mixtures having $0.5 \mathrm{w} / \mathrm{b}$ ratio did not affect thixotropy significantly.

\subsubsection{Effect of casting rate on formwork pressure}

In order to examine the effect of casting rate on formwork pressure, a pressure test was performed with two different casting rates $(5 \mathrm{~m} / \mathrm{h}$ and $10 \mathrm{~m} / \mathrm{h})$. The results of the test for a mixture with $\mathrm{w} / \mathrm{b}$ ratio of $0.50, \mathrm{CA} / \mathrm{TA}$ ratio of 0.45 and slump flow diameter of

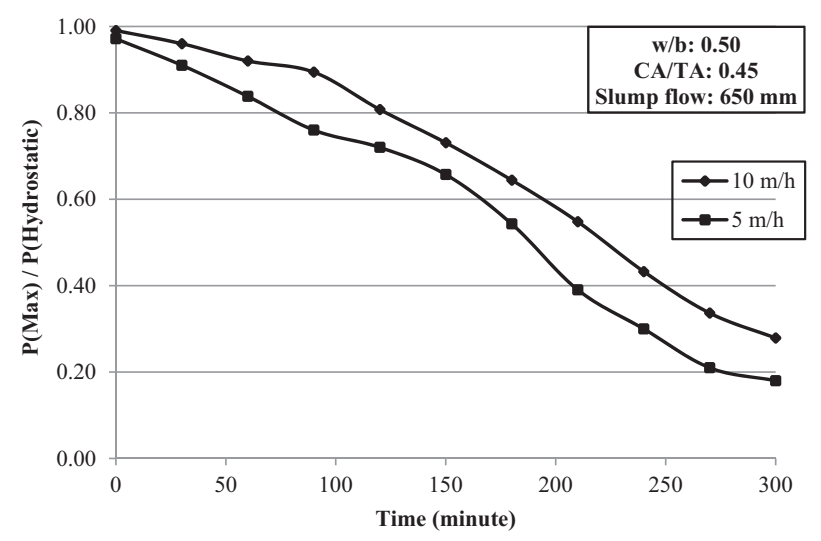

Fig. 12. Effect of casting rate on formwork pressure of SCC mixture.
$650 \mathrm{~mm}$ are shown in Fig. 12. Not surprisingly, the formwork pressure increased by increasing casting rate in all of the mixtures having $\mathrm{w} / \mathrm{b}$ ratio of 0.50 . The similar result was reported by other researchers [12]. It seems that when the casting rate increases, the concrete is exposed to a greater shear force causing rupture of the bonds arisen from thixotropy within the concrete. Thus, the fresh concrete behaves more like a liquid and exerts a higher formwork pressure. Regardless of the CA/TA ratio and slump flow value, all of the mixtures having $\mathrm{w} / \mathrm{b}$ ratio of 0.50 showed same formwork pressure - time relationship shown in Fig. 12. The result of formwork pressure tests revealed that the behavior of the mixture having $\mathrm{w} / \mathrm{b}$ ratio of 0.35 and 0.42 was different from the behavior of the mixtures with $\mathrm{w} / \mathrm{b}$ ratio of 0.50 . As it can be seen from Table 4, it cannot be clearly stated whether the low casting rate or high casting rate causes greater formwork pressure. This is because the mixtures with $\mathrm{w} / \mathrm{b}$ ratio of 0.50 have relatively lower thixotropy values (Fig. 6(a)). With both casting rates, the shear force during the casting can hardly rupture the bonds within the mixtures with higher thixotropy (and lower w/b ratio), thus, the effect of casting rate becomes less significant. In practice, the formwork pressure is of great significance and should be limited particularly in SCC mixtures. Decreasing the rate of casting causes, in turn, higher labor cost and elongates construction time. For the test conditions applied in this study, it seems that for economic considerations, it is possible to loosen the limitation on the rate of casting in SCC mixtures with low w/b ratios.

\subsection{Relationship between thixotropy and formwork pressure in SCC mixtures}

The relationships between thixotropy, determined by four different test methods, and formwork pressure of SCC mixtures are

Table 4

Formwork pressure test results with different rates of casting.

\begin{tabular}{|c|c|c|c|c|c|c|c|c|c|c|}
\hline \multirow[t]{3}{*}{ Mixture } & \multirow[t]{3}{*}{ Casting rate $(\mathrm{m} / \mathrm{h})$} & \multicolumn{9}{|c|}{ Time (minute) } \\
\hline & & 0 & 30 & 60 & 90 & 120 & 150 & 180 & 210 & 240 \\
\hline & & \multicolumn{9}{|c|}{$\mathrm{P}(\max ) / \mathrm{P}$ (hydrostatic) } \\
\hline \multirow[t]{2}{*}{$35 / 45 / 65$} & 5 & 0.98 & 0.91 & 0.88 & 0.81 & 0.76 & 0.69 & 0.59 & 0.49 & 0.35 \\
\hline & 10 & 0.95 & 0.91 & 0.87 & 0.84 & 0.82 & 0.78 & 0.73 & 0.67 & 0.56 \\
\hline \multirow[t]{2}{*}{$35 / 50 / 55$} & 5 & 0.99 & 0.86 & 0.74 & 0.62 & 0.52 & 0.42 & 0.31 & 0.22 & 0.19 \\
\hline & 10 & 1.00 & 0.81 & 0.68 & 0.56 & 0.34 & 0.22 & 0.17 & 0.14 & 0.12 \\
\hline \multirow[t]{2}{*}{$35 / 50 / 65$} & 5 & 0.96 & 0.95 & 0.93 & 0.92 & 0.80 & 0.69 & 0.60 & 0.50 & 0.44 \\
\hline & 10 & 0.99 & 0.85 & 0.75 & 0.70 & 0.63 & 0.59 & 0.58 & 0.56 & 0.52 \\
\hline \multirow[t]{2}{*}{$35 / 50 / 72$} & 5 & 0.98 & 0.94 & 0.90 & 0.86 & 0.83 & 0.79 & 0.73 & 0.69 & 0.61 \\
\hline & 10 & 0.96 & 0.94 & 0.92 & 0.90 & 0.86 & 0.84 & 0.78 & 0.72 & 0.64 \\
\hline \multirow[t]{2}{*}{$35 / 53 / 65$} & 5 & 1.00 & 0.87 & 0.80 & 0.75 & 0.68 & 0.59 & 0.52 & 0.44 & 0.32 \\
\hline & 10 & 0.95 & 0.89 & 0.83 & 0.79 & 0.67 & 0.57 & 0.47 & 0.39 & 0.29 \\
\hline \multirow[t]{2}{*}{$42 / 45 / 65$} & 5 & 0.99 & 0.88 & 0.80 & 0.72 & 0.61 & 0.54 & 0.46 & 0.37 & 0.30 \\
\hline & 10 & 0.99 & 0.92 & 0.87 & 0.81 & 0.70 & 0.58 & 0.50 & 0.36 & 0.24 \\
\hline \multirow[t]{2}{*}{$42 / 50 / 55$} & 5 & 0.99 & 0.85 & 0.75 & 0.67 & 0.55 & 0.40 & 0.36 & 0.28 & 0.22 \\
\hline & 10 & 0.96 & 0.90 & 0.79 & 0.72 & 0.58 & 0.46 & 0.36 & 0.25 & 0.17 \\
\hline \multirow[t]{2}{*}{$42 / 50 / 65$} & 5 & 0.99 & 0.90 & 0.86 & 0.79 & 0.74 & 0.67 & 0.61 & 0.54 & 0.45 \\
\hline & 10 & 0.98 & 0.91 & 0.86 & 0.79 & 0.74 & 0.58 & 0.52 & 0.34 & 0.27 \\
\hline \multirow[t]{2}{*}{$42 / 50 / 72$} & 5 & 1.00 & 0.93 & 0.89 & 0.81 & 0.76 & 0.69 & 0.60 & 0.52 & 0.44 \\
\hline & 10 & 0.99 & 0.95 & 0.93 & 0.89 & 0.84 & 0.77 & 0.73 & 0.62 & 0.57 \\
\hline \multirow[t]{2}{*}{$42 / 53 / 65$} & 5 & 0.99 & 0.89 & 0.86 & 0.80 & 0.73 & 0.62 & 0.52 & 0.38 & 0.30 \\
\hline & 10 & 0.96 & 0.89 & 0.80 & 0.75 & 0.59 & 0.48 & 0.41 & 0.33 & 0.31 \\
\hline \multirow[t]{2}{*}{$50 / 45 / 65$} & 5 & 0.97 & 0.91 & 0.84 & 0.76 & 0.72 & 0.66 & 0.54 & 0.39 & 0.30 \\
\hline & 10 & 0.99 & 0.96 & 0.92 & 0.89 & 0.81 & 0.73 & 0.64 & 0.55 & 0.43 \\
\hline \multirow[t]{2}{*}{$50 / 50 / 55$} & 5 & 1.00 & 0.90 & 0.84 & 0.73 & 0.61 & 0.50 & 0.41 & 0.37 & 0.36 \\
\hline & 10 & 1.00 & 0.94 & 0.90 & 0.85 & 0.75 & 0.66 & 0.57 & 0.44 & 0.37 \\
\hline \multirow[t]{2}{*}{$50 / 50 / 65$} & 5 & 0.98 & 0.95 & 0.87 & 0.74 & 0.62 & 0.50 & 0.39 & 0.34 & 0.31 \\
\hline & 10 & 0.99 & 0.95 & 0.89 & 0.87 & 0.78 & 0.70 & 0.63 & 0.49 & 0.37 \\
\hline \multirow[t]{2}{*}{$50 / 50 / 72$} & 5 & 1.00 & 0.99 & 0.98 & 0.88 & 0.79 & 0.70 & 0.60 & 0.55 & 0.39 \\
\hline & 10 & 0.99 & 0.97 & 0.95 & 0.94 & 0.89 & 0.84 & 0.79 & 0.70 & 0.58 \\
\hline \multirow[t]{2}{*}{$50 / 53 / 65$} & 5 & 0.98 & 0.92 & 0.85 & 0.72 & 0.67 & 0.60 & 0.47 & 0.35 & 0.23 \\
\hline & 10 & 0.98 & 0.93 & 0.86 & 0.81 & 0.79 & 0.75 & 0.62 & 0.50 & 0.39 \\
\hline
\end{tabular}


given in Table 5. In this table, linear, parabolic or exponential types of equations were established based on different classifications to observe the effect of different variables on the relationships. The correlation coefficient values greater than 0.90 were highlighted.

When the data were classified according to time, no meaningful relationship between thixotropy and formwork pressure just after mixing ( 0 . minute) was found. This is because, immediately after mixing, formwork pressure is almost equal to the hydrostatic pressure in all of the mixtures while thixotropy values change for different mixtures. The relationships were meaningful pressure and thixotropy determined by SDBA, DAV and YVR test methods observed in 90 and 150 min after mixing.

For $\mathrm{w} / \mathrm{b}$ ratio classification, in the SCC mixtures having $\mathrm{w} / \mathrm{b}$ ratio of 0.35 , correlation coefficient values for SDBA, DAV and YVR test methods were quite high (almost 1 ). In other words, a strong inverse relationship between formwork pressure and thixotropy was observed in SCC mixtures having low w/b ratio. On the other hand, for $\mathrm{w} / \mathrm{b}$ ratios of 0.42 and 0.50 , the correlation coefficient values were lower than 0.90 .

In the SCC mixtures having slump flow value of $550 \mathrm{~mm}$, correlation coefficient values for SDBA, BDP and DAV test methods were almost 1 . There was a strong negative correlation between formwork pressure and the thixotropy determined by YVR test method when slump flow was $720 \mathrm{~mm}$.

In the SCC mixtures having CA/TA ratio of 0.45 , the only strong correlation was observed for YVR method. For CA/TA ratio of 0.50 , there was a strong linear inverse relationship between formwork pressure and thixotropy determined by SDBA and YVR test methods. In the SCC mixtures having CA/TA ratio of 0.53 , there was a strong linear negative correlation between thixotropy determined by SDBA test method and formwork pressure. Besides, as the coarse aggregate content of the SCC mixtures increased, linear correlation between thixotropy determined by YVR test method and formwork pressure decreased.

Table 5

Relationships between thixotropy determined by different test methods and formwork pressure of SCC mixtures.

\begin{tabular}{|c|c|c|c|c|c|}
\hline Classification criteria & Classification & $\begin{array}{l}\text { Thixotropy } \\
\text { measurement } \\
\text { method }\end{array}$ & $\begin{array}{l}\text { Correlation coefficient of } \\
\text { trendline constituted by } \\
\text { thixotropy and formwork } \\
\text { pressure }(\mathrm{R})\end{array}$ & $\begin{array}{l}\text { Trendline } \\
\text { type }\end{array}$ & $\begin{array}{l}\text { Equation } \\
\text { (y: formwork pressure at certain time } \\
\mathrm{x} \text { : thixotropy at the same time) }\end{array}$ \\
\hline \multirow[t]{12}{*}{ Time } & \multirow[t]{4}{*}{$0 \mathrm{~min}$} & SDBA & 0.745 & Polynomial & $y=8 E-08 x^{2}-0,0001 x+0,9999$ \\
\hline & & BDP & 0.495 & Exponential & $\mathrm{y}=1,0001 \mathrm{e}^{-6 \mathrm{E}-04 \mathrm{x}}$ \\
\hline & & DAV & 0.604 & Polynomial & $y=6 E-09 x^{2}-3 E-05 x+0,9974$ \\
\hline & & YVR & 0.579 & Polynomial & $\mathrm{y}=4 \mathrm{E}-08 \mathrm{x}^{2}-0,0001 \mathrm{x}+1,0174$ \\
\hline & \multirow[t]{4}{*}{$90 \mathrm{~min}$} & SDBA & 0.766 & Polynomial & $y=-3 E-07 x^{2}+3 E-05 x+0,8536$ \\
\hline & & BDP & 0.465 & Exponential & $y=0,9196 e^{-0004 x}$ \\
\hline & & DAV & 0.816 & Exponential & $\mathrm{y}=0,9024 \mathrm{e}^{-9 \mathrm{E}-05 \mathrm{x}}$ \\
\hline & & YVR & 0.734 & Polynomial & $y=-4 E-08 x^{2}-3 E-05 x+0,8866$ \\
\hline & \multirow[t]{4}{*}{$150 \mathrm{~min}$} & SDBA & 0.806 & Exponential & $\mathrm{y}=0,866 \mathrm{e}^{-8 \mathrm{E}-04 \mathrm{x}}$ \\
\hline & & BDP & 0.389 & Polynomial & $y=0,0003 x^{2}-0,0199 x+0,9577$ \\
\hline & & DAV & 0.740 & Polynomial & $y=-3 E-08 x^{2}+3 E-05 x+0,6985$ \\
\hline & & YVR & 0.805 & Polynomial & $y=5 E-08 x^{2}-0,0003 x+0,9647$ \\
\hline \multirow[t]{12}{*}{ Water to binder ratio } & \multirow[t]{4}{*}{0.35} & SDBA & 0.971 & Exponential & $\mathrm{y}=1,7744 \mathrm{e}^{-0,002 \mathrm{x}}$ \\
\hline & & BDP & 0.664 & Polynomial & $y=-0,0065 x^{2}+0,6725 x-16,563$ \\
\hline & & DAV & 0.991 & Polynomial & $y=-2 E-08 x^{2}-8 E-05 x+1,0079$ \\
\hline & & YVR & 0.991 & Polynomial & $y=1 E-08 x^{2}-0,0003 x+0,9686$ \\
\hline & \multirow[t]{4}{*}{0.42} & SDBA & 0.860 & Polynomial & $y=3 E-06 x^{2}-0,0039 x+1,6276$ \\
\hline & & BDP & 0.711 & Polynomial & $y=-0,0015 x^{2}+0,0825 x-0,4317$ \\
\hline & & DAV & 0.747 & Polynomial & $y=-4 E-07 x^{2}+0,0015 x-0,5366$ \\
\hline & & YVR & 0.625 & Polynomial & $y=-8 E-08 x^{2}+0,0003 x+0,3339$ \\
\hline & \multirow[t]{4}{*}{0.50} & SDBA & 0.747 & Polynomial & $y=2 E-05 x^{2}-0,0056 x+1,0886$ \\
\hline & & BDP & 0.056 & Polynomial & $y=8 E-05 x^{2}-0,0032 x+0,7643$ \\
\hline & & DAV & 0.361 & Exponential & $y=0,7839 e^{-2 E-04 x}$ \\
\hline & & YVR & 0.941 & Polynomial & $y=2 E-06 x^{2}-0,0039 x+2,6798$ \\
\hline \multirow[t]{12}{*}{ Slump flow diameter ${ }^{*}$} & \multirow[t]{4}{*}{$550 \mathrm{~mm}$} & SDBA & 0.992 & Linear & $y=-0,0004 x+0,693$ \\
\hline & & BDP & 0.933 & Linear & $y=-0,0169 x+1,0255$ \\
\hline & & DAV & 1.000 & Linear & $y=-0,0001 x+0,7258$ \\
\hline & & YVR & 0.655 & Linear & $y=-0,0001 x+0,7898$ \\
\hline & \multirow[t]{4}{*}{$650 \mathrm{~mm}$} & SDBA & 0.856 & Linear & $y=-0,0002 x+0,7027$ \\
\hline & & BDP & 0.773 & Linear & $y=-0,0024 x+0,7053$ \\
\hline & & DAV & 0.726 & Linear & $y=-4 E-05 x+0,6775$ \\
\hline & & YVR & 0.964 & Linear & $y=-0,0002 x+0,8498$ \\
\hline & \multirow[t]{4}{*}{$720 \mathrm{~mm}$} & SDBA & 0.167 & Linear & $y=-3 E-05 x+0,8261$ \\
\hline & & BDP & 0.040 & Linear & $y=8 E-05 x+0,8137$ \\
\hline & & DAV & 0.154 & Linear & $y=-8 E-06 x+0,8255$ \\
\hline & & YVR & 0.983 & Linear & $y=-0,0001 x+0,91$ \\
\hline \multirow{12}{*}{$\begin{array}{l}\text { Coarse aggregate to } \\
\text { total aggregate ratio }\end{array}$} & \multirow[t]{4}{*}{0.45} & SDBA & 0.298 & Linear & $y=0,0001 x+0,6586$ \\
\hline & & BDP & 0.514 & Linear & $y=0,0029 x+0,6256$ \\
\hline & & DAV & 0.254 & Linear & $y=3 E-05 x+0,6638$ \\
\hline & & YVR & 0.993 & Linear & $y=-0,0002 x+0,8735$ \\
\hline & \multirow[t]{4}{*}{0.50} & SDBA & 0.856 & Linear & $y=-0,0002 x+0,7027$ \\
\hline & & BDP & 0.773 & Linear & $y=-0,0024 x+0,7053$ \\
\hline & & DAV & 0.726 & Linear & $y=-4 E-05 x+0,6775$ \\
\hline & & YVR & 0.964 & Linear & $y=-0,0002 x+0,8498$ \\
\hline & \multirow[t]{4}{*}{0.53} & SDBA & 0.955 & Linear & $y=-0,0004 x+0,8013$ \\
\hline & & BDP & 0.672 & Linear & $y=-0,0092 x+0,9688$ \\
\hline & & DAV & 0.331 & Linear & $y=-3 E-05 x+0,6524$ \\
\hline & & YVR & 0.254 & Linear & $y=-7 E-05 x+0,6779$ \\
\hline
\end{tabular}

\footnotetext{
* Formwork pressure data after 150 min rest.
} 
Table 6

The calculated $m$ and $n$ variables, the slope and the regression coefficients $\left(R^{2}\right)$.

\begin{tabular}{|c|c|c|c|c|}
\hline Thixotropy measurement method & $m$ & $n$ & Slope & Regression coefficient $\left(\mathrm{R}^{2}\right)$ \\
\hline SBDA & 0.0019 & 0.1955 & 0.92 & 0.84 \\
\hline BDP & 0.0056 & -0.0087 & 0.91 & 0.87 \\
\hline DAV & 0.0018 & 0.1682 & 0.91 & 0.85 \\
\hline YVR & 0.0001 & 0.5994 & 0.96 & 0.87 \\
\hline
\end{tabular}

\subsection{Model development for formwork pressure}

Several models are available in the literature to predict the formwork pressure of SCC [17,24-36]. This study aimed to develop a new model for the same purpose. The model developed in this study is based on the model proposed by Lange et al. [25] and Tejeda-Dominguez [29] which is:

$\mathrm{P}_{\mathrm{h}}=\gamma * \mathrm{R} * \mathrm{t} * \mathrm{C}(\mathrm{t})$

where, $\mathrm{P}_{\mathrm{h}}$ is the lateral pressure $(\mathrm{kPa}), \gamma$ is the unit weight of concrete $\left(\mathrm{kN} / \mathrm{m}^{3}\right), \mathrm{R}$ is the casting rate $(\mathrm{m} / \mathrm{h})$ and $\mathrm{t}$ is time $(\mathrm{h})$. The $\gamma$ Rt term refers to the hydrostatic pressure and the $\mathrm{C}(\mathrm{t})$ term is to evaluate the decay in the pressure with time. $\mathrm{C}(\mathrm{t})$ was proposed to be a hyperbolic function as given in the following equation:

$\mathrm{C}(\mathrm{t})=\frac{\mathrm{C}_{0}}{\left(a * \mathrm{t}^{2}+1\right)^{\alpha}}$

where $C(t)$ is the characteristic pressure decay as a function of time, $\mathrm{C}_{0}$ is the initial pressure, and $a$ and $\alpha$ are time-dependent variables. In several studies [25,36], $\alpha$ was taken as 12 and the variable $a$ was calculated for each mixture considering the measured pressure data.

Although it is known from the literature [10,23] and Section 3.3 that the formwork pressure of SCC is affected by its thixotropy, the model of Lange et al. [25] and Tejeda-Dominguez [29] does not explicitly consider the thixotropy of SCC. Since the parameter $a$ changes depending on the mixture characteristics, in this study, it is expressed in terms of thixotropy. In this way, the measured thixotropy values can be included in the model.

In the proposed model, the variable $a$ was defined as:

$a=m * T^{n}$

where $T$ is thixotropy (determined by different methods), $m$ and $n$ are empirical variables. Then, the decay function $C(t)$ is defined in the new model as:

$\mathrm{C}(\mathrm{t})=\frac{\mathrm{C}_{0}}{\left(m * T^{n} * \mathrm{t}^{2}+1\right)^{12}}$

The variables $m$ and $n$ were optimized by minimizing the rootmean square errors resulting from the comparison of the actual and the model results. The data used for calculating the $m$ and $n$ belonged to a casting rate of $10 \mathrm{~m} / \mathrm{h}$. The values of $m$ and $n$ were calculated for each of the thixotropy method. Then the model with the calculated $m$ and $n$ was used to predict the decay in the formwork pressure for casting rate of $5 \mathrm{~m} / \mathrm{h}$. These values, the slope of the linear trendline that correlates the actual decay values and the predicted decay values, as well as the regression coefficients $\left(R^{2}\right)$ are given in Table 6. As an example, the relationship between the actual vs. predicted decay for the YVR method is shown in Fig. 13. The models involving different thixotropy measurements were compared in Fig. 14 for the 35/45/65 mixture. Most of the figures for the other mixtures were similar to Fig. 14, therefore, all of them were not included in this manuscript.

Table 6 shows that all of the models resulted in quite high $(>0.84)$ regression coefficients $\left(R^{2}\right)$. The prediction with BDP and YVR methods were slightly better than the other methods when

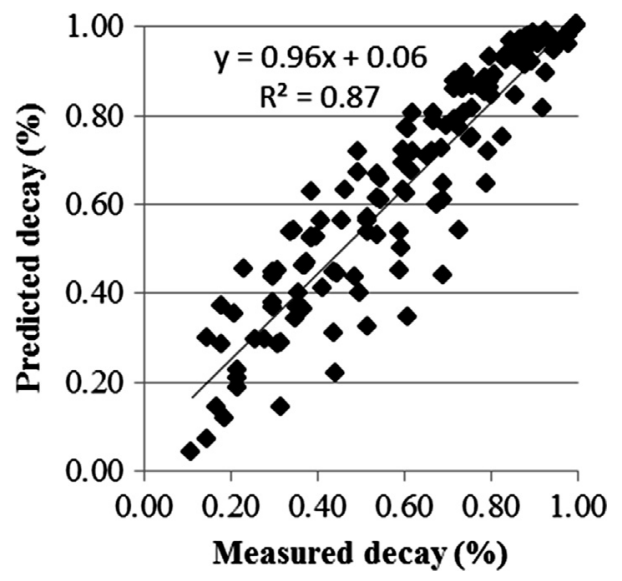

Fig. 13. Predicted vs. measured decay for the YVR model.

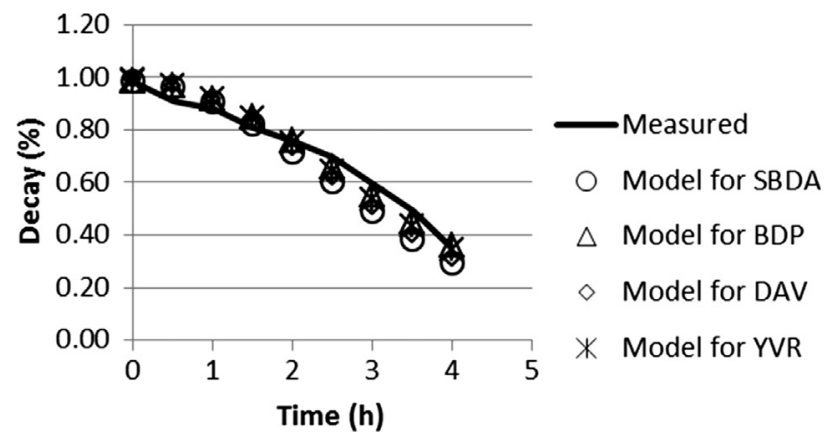

Fig. 14. Comparison of the models with the measured data for 35/45/65 mixture.

the regression coefficients are compared. The slope of the YVR model was the closest one to unity, indicating the superiority of it over the others. Fig. 14 also proves the success of all of the models.

\section{Conclusions}

In this study, the thixotropy and formwork pressure of SCC mixtures having different water/binder ratios, slump flow diameters and coarse aggregate/total aggregate ratios were determined. Thixotropy was determined by four different methods and the formwork pressure was recorded continuously up to $6 \mathrm{~h}$. For the relationship between the thixotropy and formwork pressure, regarding the materials used and the test methods applied, the following conclusions can be drawn:

- The thixotropy values measured with SDBA, DAV, and YVR methods reduced by increasing water/binder ratio and slump flow of the SCC mixtures. The thixotropy of the mixtures having low water/binder ratios decreased by increasing coarse aggregate to total aggregate ratio. However, the effect of coarse aggregate to total aggregate ratio on thixotropy was less pronounced in the mixtures of high water/binder ratios. 
- Among the four methods of measuring thixotropy, BDP method was found to be the least reliable one.

- The gradual fall in lateral pressure was influenced by the water/ binder ratio of the mixtures having low slump flow value. The effect of water/binder ratio on the lateral formwork pressure diminished by increasing slump flow value.

- For the mixtures with higher water/binder ratio, the formwork pressure increased by increasing rate of casting. This was not the case in the mixtures having lower water/binder ratios.

- There was an inverse relationship between thixotropy and formwork pressure of SCC mixtures. The gradual fall in formwork pressure occurred more rapidly when SCC mixtures had higher thixotropy. The correlation between thixotropy and formwork pressure was better in SCC mixtures having lower water/binder ratio.

- With SDBA, DAV and YVR test methods, a strong relationship between thixotropy and formwork pressure was determined in the mixtures having lower water/binder ratio. Regardless of the method used to determine the thixotropy, in the mixtures having higher water/binder ratios, no meaningful relationship between the thixotropy and formwork pressure was found.

- There was a strong relationship between thixotropy obtained by SDBA, BDP and DAV test methods and formwork pressure in the mixtures having low slump flow value. However, in the mixtures having higher slump flow value, the thixotropy obtained by YVR test method showed a strong relationship with the formwork pressure.

- The linear correlation between thixotropy determined by YVR test method and formwork pressure diminished with increasing the coarse aggregate content of the SCC mixtures.

- All of the models were able to predict the pressure decay successfully. The prediction with the YVR method was found to be better than that of the other methods.

\section{Conflict of interest}

None.

\section{Acknowledgements}

The authors would like to thank The Scientific and Technical Research Council of Turkey (TUBITAK) for the financial support provided under Project: MAG 109 M615.

\section{References}

[1] EFNARC. The European Guidelines for Self Compacting Concrete. www.efnarg. org, 2005.

[2] H. Okamura, K. Ozawa, Mix-design for self-compacting concrete, Concrete Library JSCE 25 (1995) 107-120.

[3] K.H. Khayat, Workability, testing, and performance of self-consolidating concrete, ACI Mater. J. 96 (3) (1999) 346-353.

[4] H. Okamura, M. Ouchi, Self-compacting concrete, J. Adv. Concr. Technol. 1 (1) (2003) 5-15.

[5] P.K. Mehta, P.J.M. Monteiro, Concrete, Microstructure, Properties, and Material, 3rd ed., McGraw-Hill, New York, 2006.

[6] J.H. Kim, M.W. Beacraft, S.H. Kwon, S.P. Shah, Simple analytical model for formwork design of self-consolidating concrete, ACI Mater. J. 108 (1) (2011) 38-45.

[7] H.A. Barnes, Thixotropy - A review, J. Nonnewton Fluid Mech. 70 (1997) 1-33.

[8] K.H. Khayat, J.J. Assaad, Effect of $w / \mathrm{cm}$ and high-range water-reducing admixture on formwork pressure and thixotropy of self-consolidating concrete, ACI Mater. J. 103 (3) (2006) 186-193.

[9] J.J. Assaad, K.H. Khayat, H. Mesbah, Assessment of thixotrophy of flowable and self- consolidating concrete, ACI Mater. J. 100 (2) (2003) 111-120.

[10] J. Assaad, Formwork Pressure of Self-consolidating Concrete Influence of Thixotropy (PhD Thesis), University of Sherbrooke, Canada, 2004.

[11] A.S. Hanna, Concrete Formwork Systems, Marcel Dekker, USA, 1999.
[12] P. Billberg, Form pressure generated by self-compacting concrete, in: 3rd International Symposium on Self-Compacting Concrete, Reykjavik, Iceland, 2008:271-80.

[13] K.H. Khayat, J.J. Assaad, Measurement systems for determining formwork pressure of highly flowable concrete, Mater. Struct. 41 (1) (2008) 37-46.

[14] K.H. Khayat, A. Omran, S. Neji, P. Billberg, A. Yahia, Test methods to evaluate form pressure of SCC, in: The Third North American Conference on the Design and Use of Self Consolidating Concrete, Chicago, USA, 2008:308-314.

[15] A. Gregori, R.P. Ferron, Z. Sun, S. Shah, Experimental simulation of selfconsolidating concrete formwork pressure, ACI Mater. J. 105 (1) (2008) 97104.

[16] Centre Experiméntal du Bâtiment et des Travaux Publics (CEBTP) The validated technique of self compacting concrete. Report No. B242-9-054, 1999:12 pp.

[17] G. Ovarlez, N. Roussel, A physical model for the prediction of lateral stress exerted by self-compacting concrete on formwork, Mater. Struct. 39 (286) (2006) 269-279.

[18] D. Lange, Y.S. Liu, How tall, how fast, how safe? New insights into formwork pressure of self consolidating concrete, Concr. Constr. Mag. (2008).

[19] J. Assaad, K.H. Khayat, Formwork pressure of self-consolidating concrete made with various binder types and contents, ACI Mater. J. 102 (4) (2005) 215-223.

[20] J. Assaad, K.H. Khayat, Kinetics of formwork pressure drop of self-consolidating concrete containing various types and contents of binder, Cem. Concr. Res. 35 (8) (2005) 1522-1530.

[21] J.J. Assaad, K.H. Khayat, Effect of casting rate and concrete temperature on formwork pressure of self-consolidating concrete, Mater. Struct. 39 (287) (2006) 333-341.

[22] J.J. Assaad, K.H. Khayat, Effect of viscosity-enhancing admixtures on formwork pressure and thixotropy of self-consolidating concrete, ACI Mater. J. 103 (4) (2006) 280-287.

[23] J.J. Assaad, K.H. Khayat, H. Mesbah, Variation of formwork pressure with thixotropy of self-consolidating concrete, ACI Mater. J. 100 (1) (2003) 29-37.

[24] K.H. Khayat, A.F. Omran, Field monitoring of SCC formwork pressure and validation of prediction models, Concr. Int. 33 (6) (2011) 33-39.

[25] D.A. Lange, B. Birch, J. Henchen, Y.-S. Liu, F. Tejeda-Dominguez, L. Struble Modeling formwork pressure of SCC, in: S.P. Shah (Ed.), Proceedings of the 3rd North American Conference on the design and use of self-consolidating concrete. Chicago, USA, 2008, pp. 295-300.

[26] N.J. Gardner, L. Keller, R. Quattrociocchi, G. Charitou, Field investigation of formwork pressures using self-consolidating concrete, Concr Int 34 (1) (2012) 41-47.

[27] C.-A. Graubner, E. Boska, C. Motzko, T. Proske, F. Dehn, Formwork pressure induced by highly flowable concrete - Design approach and transfer in practice, Struct. Concr. J. Fib. Ernst \& Sohn Verlag (2012).

[28] A. Perrot, S. Amziane, G. Ovarlez, N. Roussel, SCC formwork pressure: influence of steel rebars, Cem. Concr. Res. 39 (6) (2009) 524-528.

[29] F. Tejeda-Dominguez, Laboratory and Field Study of Self-Consolidating Concrete Formwork Pressure (M.Sc. Thesis), University of Illinois at UrbanaChampaign, 2005.

[30] T. Proske, Frischbetondruck bei verwendung von selbstverdichtendem beton Ein wirklichkeitsnahes modell zu bestimmung der einwirkungen auf schalung und rüstung (Formwork pressure using self-compacting concrete). PhD-thesis. Technische Universität Darmstadt, 2007.

[31] T. Proske, C.-A. Graubner, Pressure on Formwork using SCC - Experimental Studies and Modeling, Proceedings of the fifth RILEM international symposium on self-compacting concrete. Ghent, 2007.

[32] DIN 18218:2010-01. Frischbetondruck auf lotrechte schalungen (Pressure of fresh concrete on vertical formwork). Beuth Verlag, 2010.

[33] M. Beitzel, Modeling fresh concrete pressure of normal and self-compacting concrete, in: K.H. Khayat, D. Feys (Eds.), Proceedings of SCC2010, the 6th international RILEM symposium on SCC and the 4th North American conference on the design and use of self-consolidating concrete. Montreal, Quebec, Canada, 2010, pp. 243-254.

[34] J.H. Kim, M. Beacraft, S.P. Shah, Effect of mineral admixtures on formwork pressure of self-consolidating concrete, Cem. Concr. Compos. 32 (2010) 665671.

[35] N.R. Andriamanantsilavo, S. Amziane, Maturation of fresh cement paste within 1- to 10-m-large formworks, Cem. Concr. Res. 34 (2004) 2141-2152.

[36] P. Billberg, N. Roussel, S. Amziane, M. Beitzel, G. Charitou, B. Freund, J.N. Gardner, G. Grampeix, C.A. Graubner, L. Keller, K.H. Khayat, D.A. Lange, A.F. Omran, A. Perrot, T. Proske, R. Quattrociocchi, Y. Vanhove, Field validation of models for predicting lateral form pressure exerted by SCC, Cem. Concr. Compos. 54 (2014) 70-79.

[37] EN 1097-6. Tests for mechanical and physical properties of aggregates-part 6 : determination of particle density and water absorption. European Standard, Brussels, 2002.

[38] R. Lapasin, A. Papo, S. Rajgelj, Flow behavior of fresh cement pastes. A comparison of different rheological instruments and techniques, Cem. Concr. Res. 13 (1983) 349-356.

[39] O.C.C. Lin, Chem. Tech. 5 (1) (1975) 51-62.

[40] N.Q. Dzuy, D.V. Boger, Direct yield stress measurement with the vane method, J. Rheol. 29 (1985) 335-347.

[41] ASTM C 403. Standard Test Method for Time of Setting of Concrete Mixtures by Penetration Resistance. ASTM International, 1999. 